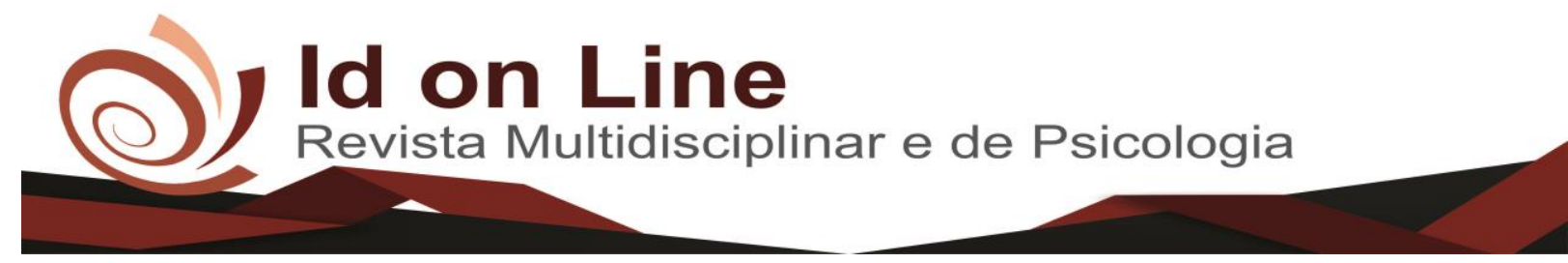

Comment

\title{
Importância do Terceiro Setor como alternativa de Gestão no aparato social
}

\author{
Micheiane Felix de Brito ${ }^{1}$; Maria Natália da Silva Tavares²; \\ Rita Cristiane Ramacciotti Gusmão Soares ${ }^{3}$
}

\begin{abstract}
Resumo: As instituições sem fins lucrativos que compõem o terceiro setor, têm demonstrado ser uma alternativa para as questões sociais, com resultados visíveis, que visam amenizar os problemas de uma parcela da sociedade mais carente. Infelizmente essas instituições contam com grandes e constantes desafios para se manterem sustentáveis. Essa sustentabilidade se dá na maneira como as entidades administram seus trabalhos buscando soluções essenciais para execução de suas atividades. Esse estudo de cunho qualitativo e bibliográfico propõe a principal afirmação de pesquisa: "Importância do terceiro Setor como alternativa de gestão no aparato social". Esse artigo tem como objetivo evidenciar a grande importância desse setor da economia no aparato social, considerando a grande ausência e falha do Estado nas demandas da sociedade. No decorrer da pesquisa, observouse que o maior desafio enfrentado na gestão dessas instituições para as demandas sociais é a captação de recursos. Assim, verificou-se que uma gestão eficiente, capacitada, dinâmica e proativa, junto a parceria dos setores público e privado, e o reconhecimento da sociedade, possibilitam a continuação e a sustentabilidade das instituições.
\end{abstract}

Palavra Chave: Terceiro Setor, Sociedade, Governo, Mercado, Gestão

\section{Importance of the Third Sector as an alternative of the social apparatus Management}

\begin{abstract}
The non-profit institutions that make up the third sector have been shown to be an alternative to social issues, with visible results, which consist to soften problems of a portion of the most deprived society. Unfortunately these institutions have great and constant challenges to remain sustainable. This sustainability takes place in the way the entities manage their work searching for essential solutions to carry out their activities. This qualitative and bibliographical study proposes the main research statement: the importance of the third Sector as an alternative of management in the social apparatus. This article aims to highlight the great importance of this sector of the economy in the social apparatus, considering the great absence and failure of the State in the demands of society. In the course of the research, it was observed that the greatest challenge faced in the management of these institutions for social demands is the fundraising. Thus, it was verified that a efficient, proactive, dynamic and proactive management, together with the partnership of the public and private sectors and the recognition of society enables the continuation and sustainability of the institutions.
\end{abstract}

Keywords: Third Sector, Society, Government, Market, Management

\footnotetext{
1 Bacharela em Ciências Contábeis - FACAPE. Pós-Graduada em Gestão Pública - UNIVASF. Contato: micheianecont.fbrito@gmail.com;

2 Bacharela em Ciências Contábeis - FACISA. Pós-Graduada em Gestão Pública - UNIVASF. Contato: ntavarescontabilidade12@gmail.com;

${ }^{3}$ Doutora em Ciências da Educação-USM. Mestra em Desenvolvimento Humano e Responsabilidade Social- FVC. PósGraduada em Metodologia do Ensino Superior- FOM. Graduada em Ciências Econômicas- FACCEBA.

Pedagogia-FAA. Contato: cristianegusmao@gmail.com.
} 


\section{Introdução}

Na relação Sociedade-Estado, a ação gerencial dialógica - gestão social, a cidadania deliberativa sugere que os indivíduos ao tomarem conhecimento de sua existência como sujeito social e não associado, ou seja, tendo pleno conhecimento de seu papel na sociedade, estes devem participar ativos e solidários nos destinos de sua comunidade e não somente colaborando como eleitores.

Ainda se tratando dessa relação Sociedade - Estado, outro elemento que surgiu e vem gradualmente buscando lugar no mercado é o denominado "terceiro setor", sendo caracterizado como o espaço da sociedade civil, a posição privilegiada da integração social, da intersubjetividade pleiteada por uma gestão mais solidária.

Atualmente, o denominado terceiro setor tem sido a saída para muitos problemas sociais que abalam a sociedade contemporânea. Os sistemas-governo com suas perspectivas de Estado Mínimo, assim como os sistemas-empresa, estabelecendo estratégias de ação social, ora propõem parcerias, ora deixam por conta do setor mencionado acima a responsabilidade para atender as deficiências sociais, segundo (Tenório, Fernando Guilherme 2008. p. 9) em uma de suas ilustres obras, relatando também a existência de menos ação de governo e mais de mercado.

Por essa razão, e para entendimento da denominação e surgimento do terceiro setor esse trabalho propõe enfatizar a sua importância no aparato da política pública de maneira a pautar sociedade-governo, sem a inversão de valores.

A expressão Terceiro Setor conforme TACHIZAWA (2002, p. 24) surgiu do inglês Third Sector que faz parte do seu vocabulário sociológico. Nos Estados Unidos Third Sector é usada paralelamente à expressão Non Profit Organizations, que significam organizações sem fins lucrativos. Na Europa, as organizações pertencentes a este setor são conhecidas como Organizações Não-Governamentais (ONGs), ambas denominações são organizações civis de direito privado com fins públicos e não lucrativos.

No Brasil não é diferente, a questão social é algo que move muitas pessoas, principalmente aquelas que ativamente prestam serviços direta ou indiretamente. Como aborda aspecto social, não poderia ser diferente, interfere na política e na economia nas três esferas de governo - municipal, estadual e federal. 
Segundo Tachizawa (2002, p.24),

... as ONGs, historicamente, começaram a existir em anos de regime militar, acompanhando um padrão característico da sociedade brasileira, onde o período autoritário convive com a modernização do país e com o surgimento de uma nova sociedade organizada, baseada em ideários de autonomia em relação ao Estado, em que sociedade civil tende a confundir - se, por si só, com oposição política.

As ONGs constroem-se e consolidam - se à medida que se cria e fortalece amplo e diversificado campo de associações civis, a partir principalmente dos anos 70 processo que caminha em progressão geométrica pelas décadas de 80 e 90 . As ONGs fazem parte desse processo e representam um papel em seu desenvolvimento.

Com a adoção do neoliberalismo e a "falência do Estado", ou seja, não disponibilizando mais de estrutura governamental mediante as gestões que resolvesse as demandas da população frente as necessidades, seja por incapacidade ou desinteresse, o governo infelizmente ainda não dispõe de total competência para combater ou mesmo subsidiar os problemas sociais. Nessa dificuldade enfrentada pelo Estado, vai ganhando lugar cada vez mais o Terceiro Setor, porque conseguem mesmo que gradativamente preencher várias lacunas deixadas pelo poder público nas diferentes áreas demandadas, como: saúde, educação, assistência social, cultura, recreação, agricultura e etc.

\section{Objetivo Geral}

Fundamentando-se nos conceitos existentes, pensamentos ordenados através da leitura de alguns autores, essa pesquisa tem o propósito de mostrar O Terceiro Setor como opção de gestão dentro das demandas da sociedade, buscando meios de sustentabilidade.

\section{Objetivos específicos}

- Considerar a importância e conceitos adotados de Gestão Pública;

- Aprofundar sobre o surgimento do Terceiro Setor na economia;

- Analisar o terceiro setor como elemento necessário para a sociedade e estado;

- Verificar os benefícios disponíveis mediante uma gestão habilitada no Terceiro Setor;

- Observar o quão é importante fiscalizar e controlar o que é de todos; e 
- Explanar ação de inúmeras Organizações Não Governamentais existentes;

\section{Explanação concisa de Gestão pública e orçamento público}

Malmegrin (2012 p. 12) afirma que o termo gestão é sinônimo de administração e significa um conjunto de princípios, de normas e de funções que têm por fim ordenar os fatores de produção e controlar a sua produtividade e a sua eficiência, para obter determinado resultado.

Gestão pública é a expressão usada para garantir a compreensão mais ampla do orçamento público e aplicabilidade justa e responsável desses recursos nos programas de governo. Os interesses populares pela gestão dos recursos públicos, no Brasil, se originaram na época da prosperidade colonial, quando várias lideranças nos diversos seguimentos sociais, traziam em sua bagagem cultural, os ideais democráticos comparados com seus estudos, assim explica Bezerra Filho (2006, p. 1) em uma de suas obras.

Entende-se que a gestão quando bem planejada e elaborada consegue fazer o que tem que ser feito, obedecendo os limites de recursos alcançando e os resultados almejados. Outra compreensão lógica é a capacidade de gestão aplicada, pois sua maneira irá refletir direto, ou indiretamente na relação financeira e execução, trazendo para as instituições concepções distintas de administração.

Entendemos então que não se separam gestão pública de orçamento público e programas governamentais, são elementos que se complementam e apresentam conceitos diferentes, Bezerra Filho (2006, p. 05) cita em sua obra que orçamento público constitui-se como.

Ferramenta legal de planejamento do estudo onde são apresentadas as receitas previstas e despesas fixadas que serão realizadas pelo ente, em um determinado período, objetivando a execução de programas de governo (manutenção e investimentos), bem como as transferências legais e voluntárias, os pagamentos de dívidas e outros encargos decorrentes da dívida estatal.

Ainda, Bezerra Filho (2006, p. 5) citando Forte (1996, p.55) diz ser um processo de planejamento contínuo e dinâmico de que o Estado se utiliza para demonstrar seus planos e programas de trabalho, para determinado período. $\mathrm{O}$ orçamento abrange a manutenção das 
atividades do Estado, o planejamento e a execução dos projetos estabelecidos nos planos e programas de governo.

Assim, observa-se que todo processo de gestão necessita de um orçamento prévio, que possibilite a manutenção decorrente das despesas de qualquer instituição. Ele viabiliza ao gestor independente onde esteja atuando, se numa esfera pública ou privada, permitindo que a excelência na forma de gerir cubra todos os percalços existentes, fazendo como que tenha êxito os resultados esperados.

\title{
Importância do Terceiro Setor
}

A atuação da sociedade civil organizada e o relacionamento das entidades privadas com a administração pública têm merecido imensa expansão nas últimas décadas.

Rosa, Márcio Fernando Elias (2012, P. 97) explica em sua obra que:

\begin{abstract}
A expressão Terceiro Setor, que não provém das ciências jurídicas, mas de outras ciências sociais (sociologia), quer indicar o conjunto de organizações não governamentais criadas para o desempenho de atividades socialmente relevantes. É empregada nos Estados Unidos (Third Sector - Non Profit Organizations) para identificar as entidades privadas e sem fins lucrativos.
\end{abstract}

A importância social e jurídica dessas entidades privadas é intensa. Atuam como peça necessária da sociedade civil, estabelecem ligações de solidariedade, instiga o voluntariado e, com isso, ajudam a construção de uma nova realidade social. Interferem decisivamente na vida enquanto sociedade e exigem sempre do Estado posturas políticas como o reconhecimento de políticas sociais.

Ainda conforme Rosa, Márcio Fernando Elias (2012, P. 98) cabe ao Estado cumprir, sobretudo, o desempenho da atividade de fomento, de incentivo à criação e atuação dessas entidades, mas deve fazê-lo com respeito aos princípios próprios do regime jurídico da Administração, sem prejuízo, portanto, da legalidade, da impessoalidade, da moralidade, da publicidade e da eficiência.

Nesse sentido, observa-se que a atuação do Terceiro Setor é primordial para os valores populares, seja para a mudança de paradigma e para a consecução de interesses coletivos. São importantes e necessárias porque trabalham sem o interesse de obter lucros, ou especulativo, 
não detendo poder político e sim social. Em decorrência do seu propósito, ganhou espaço conseguindo fazer parte do mercado, onde no seu aparato e em parceria com o Estado, mediante certames, cooperações e várias formas de assistências, executam diversos trabalhos extraordinários, eficientes, capazes de modificar muitas realidades sociais através da gestão.

\section{Terceiro Setor, Sociedade e Estado}

Nos últimos anos, o designado terceiro setor tem sido apontado como uma saída para vários problemas sociais que afetam a sociedade moderna. O Estado, nas suas perspectivas administrativas junto ao mercado, estabelece estratégias de ação social na forma individual ou coletiva, sendo essa última, mediante parcerias, e ainda, quando a estratégia não funciona como o esperado, deixam por conta do $3^{\circ}$ setor da economia, transferindo total responsabilidade para atuarem atendendo as deficiências social. Essas entidades conferem características singulares, assim menciona Rosa (2012, p.108):
a) não integram o aparelho governamental;
b) não distribuem lucros a acionistas ou investidores, nem tem tal finalidade;
c) se auto gerenciam e gozam de alto grau de autonomia interna;
d) envolvem um serviço significativo de participação voluntária; e
e) suas ações são direcionadas a provocar mudanças de comportamento.

Tenório, Fernando Guilherme (2008, p. 41) afirma que o processo de institucionalização do terceiro setor, também conhecido como setor sem fins lucrativos, traz características em contraste com o primeiro e o segundo, e foi implementado nos anos 70 para a promoção de atividades de caráter público, mediante ação de diferentes agentes sociais: associações profissionais ou voluntárias, entidades de classe, fundações privadas, instituições filantrópicas, movimentos sociais, ONG's e outras organizações, sendo que além dessa classificação ainda existem tantas outras, ou seja um leque de possibilidades de enquadramento das organizações que englobam este setor, a medida que ele atua em diferentes frentes e com diferentes metodologias.

Ainda segundo Tenório, Fernando Guilherme (2008, p. 42) citando Fernandes, Rubens Cesar (1994, p. 20) comenta que na discussão sobre a denominação terceiro setor, existem aqueles que advogam que, na realidade, este setor deveria ser o primeiro, à medida que a sua 
antecedência lógica e histórica prevaleceria sobre o Estado e o capital. Por sua vez, as dicotomias organizações não lucrativas versus lucrativas e público versus privado, são também estimuladoras dessa discussão. Essa diferença pode ser entendida da seguinte forma:

\begin{tabular}{|cc|c|c|}
\hline AGENTES & & FINS & SETOR \\
\hline Privados & Para & Privados & Mercado \\
\hline Públicos & Para & Públicos & Estado \\
\hline Privados & Para & Públicos & Terceiro Setor \\
\hline Públicos & Para & Privados & Corrupção \\
\hline
\end{tabular}

Fonte: Fernandes, 1994, p. 20.

A compreensão singela sobre a institucionalização do terceiro setor, é que sua legitimação tem sido medida pelo desempenho, capacidade e efetividade, sendo o principal instrumento de solução das mazelas da sociedade. Desempenho notado em diferentes contextos da sociedade, seja rica ou pobre. Esse instrumento social vem modificando vários cenários de modo positivo, facilitando e orientando muitas vezes o próprio Estado nas melhorias para população, principalmente a mais carente, pois em alguns casos, agentes deste setor assumem um papel valioso na busca por justiça social, quando nas muitas vezes que esse êxito não é extraído pelo Estado, nem pelo setor privado, seja pela falta de interesse ou incapacidade de promover as melhorias.

\section{Os benefícios de uma Gestão hábil}

Sendo o Terceiro Setor instrumento alternativo de gestão para as questões sociais e também ambientais, dependendo da atuação das instituições, foi provado através da capacidade gerencial e administrativa em demonstrar clara e eficientemente que seu papel social transborda os mais elevados interesses de coletividade. Essas entidades sem fins lucrativos já demonstraram para que vieram, no entanto não conseguem sobreviver sem recursos financeiro, incumbindo então a influência forte de uma excelente gestão para continuarem seus interesses públicos. 
Segundo Benício (apud GUIMARÃES, p. 24), na captação de recursos, é importante distinguir o que é orçamento e o que é planejamento.

No orçamento, se supõe o quanto se aplicará de um determinado recurso numa certa atividade. No planejamento financeiro dispõem-se desses recursos para investir numa determinada atividade.

Esse conceito fez com que algumas organizações tivessem a enorme preocupação de adquirir conceitos empresariais, oferecendo avanço para algumas organizações em relação a planejamento, organização, estrutura, avaliação, auditorias.

$\mathrm{Na}$ verdade, não basta somente captar recursos, é preciso controlar e calcular minuciosamente todas as receitas e despesas das instituições sociais, sejam oriundas de recursos públicos ou da iniciativa privada.

Ainda, conforme Benício apud Guimarães (2008, p. 25) cita na sua obra que, o orçamento é um instrumento de gestão contábil necessário às entidades públicas, privadas e do Terceiro Setor, explanando que o orçamento é um instrumento útil quando:
a) É elaborado com a mesma intensidade do desejo;
b) É aceito como um instrumento de orientação;
c) É respeitado em seus limites; e
d) É revisto periodicamente.

Sendo, geralmente, entidades dependentes de recursos externos, alguns requisitos são importantes à obtenção de recursos financeiros, público ou privados, tais como:

a) Que a entidade seja formalizada;

b) Ter um bom projeto;

c) Estar em dia com a contabilidade da entidade;

d) Transparência de gestão contábil e financeira; e

e) Detentora de alguma qualificação.

Enfim, uma boa gestão é fundamental para transformar o planejamento em resultados positivos, otimizando a alocação dos recursos, diminuindo as surpresas que possam surgir e trazendo uma maior eficiência nos seus resultados desejados. Essas instituições com seus excelentes trabalhos, fornecendo informações, transparência e principalmente retorno social, oportunizam confiança, credibilidade e notadamente fidelizam seus mantenedores, mediante 
seus serviços oferecidos, na busca por uma sociedade mais justa, mais igualitária, mais humana, sensibilizando não só o Estado, mas, empresas e sociedade nas parcerias continuadas, beneficiando todos.

\section{Importância de fiscalizar e controlar}

Conforme dispõem as leis federais disciplinadoras do contrato de gestão e do termo de parceria, a fiscalização das Organizações Sociais e das Oscips é de responsabilidade do órgão do Poder Público da área de atuação correspondente à atividade fomentada (art. $8^{\circ}$ da Lei ${ }^{\circ}$ 9.637/98 e art. 11 da Lei n ${ }^{\circ}$ 9.790/99). A atuação dos Tribunais de Contas, no que concerne à fiscalização dos referidos instrumentos, dependeria de notificação pelos responsáveis dos órgãos supervisores acerca de eventuais irregularidades ou ilegalidades na utilização de recursos ou bens de origem pública pelas entidades supervisionadas (art. $9^{\circ}$ da Lei $\mathrm{n}^{\circ}$ 9.637/98 e art. 12 da Lei $n^{\circ}$ 9.790/99).

Art. 70. A fiscalização contábil, financeira, orçamentária, operacional e patrimonial da União e das entidades da administração direta e indireta, quanto à legalidade, legitimidade, economicidade, aplicação das subvenções e renúncia de receitas, será exercida pelo Congresso.

Nesse contexto, o presente artigo ressalta também a importância desempenhada pelos Tribunais de Contas em face da participação cada vez mais frequente de entidades do terceiro setor na prestação de serviços públicos, mediante incentivo estatal concedido sob diversas formas. Com isso essas entidades ficam submetidas a prestação de contas para seu financiador, que é desde uma pessoa física, empresas privadas e o próprio Estado, tanto eles como a própria sociedade obtêm o poder de fiscalizar os serviços prestados por essas empresas, já que captam recursos financeiros, ou parceria na execução de suas notórias atividades.

Nessa situação, se faz necessário fiscalizar veemente as instituições desse seguimento específico, pelas várias ocorrências que são anunciadas na mídia sobre desvio de recursos públicos, envolvendo gestores e agentes públicos, utilizando-se desse setor para receber recursos financeiros com interesses particulares, ao invés de colaborarem com o bem comum, e para disfarçarem seus interesses, nas prestações de contas, seguem todos os critérios ludibriando a fiscalização. No entanto, esquecem que nada é totalmente oculto e para sempre, 
porque a sociedade, com o apoio ou não da mídia vem gradualmente compreendendo o seu valioso papel enquanto cidadão, na busca por seus direitos e deveres.

Ainda, diante de várias leituras singelas na área consolidou-se a compreensão, que é importante ressaltar que diversas entidades, para executar qualquer projeto de finalidades específicas a sua instituição, primeiramente devem ficar atentas as chamadas de certames, sendo obrigadas a obedecer todo o edital destinado aquele fim, passando por todos os processos e cumprindo-os, e quando o recurso for creditado em conta aberta exclusivamente ao referido projeto, poderão, então iniciar as atividades sem desviar o cronograma (físico e financeiro), recebendo sempre o apoio do financiador no decorrer do projeto em execução.

\section{Exemplo de ações de entidades do Terceiro Setor}

Quando falamos de ações nesse seguimento é porque existe um universo grandioso de instituições privadas que focalizam sua intenção em mudar a realidade de pessoas, comunidades, localidades, enfim, melhorar a realidade vivida por indivíduos de diversos lugares que acreditam nessas instituições sérias, e buscam o amparo para superar as dificuldade vivenciadas.

Assim, exemplificaremos o valioso trabalho do Instituto Regional da Pequena Agropecuária Apropriada - IRPAA, que é uma organização não governamental, que há mais de trinta anos tem uma atuação na região Semiárida do Brasil, localizada em Juazeiro- BA, desenvolvendo ações técnico-educativas, embasadas na proposta de Convivência com o Semiárido, e atuando com um vasto número de projetos nacionais e internacionais em parceria com as comunidades, pessoas físicas, empresas privadas e setor público. Dentre esses projetos explanaremos sobre o ATER e sua finalidade.

Nos últimos anos vêm executando ações de ATER, com recursos públicos, dos governos estadual e federal. O trabalho de ATER, através do IRPAA, busca estimular ao público beneficiário a conhecer melhor as especificidades da região, as características climáticas, a sustentabilidade dos agro-ecossistemas e a produção de base familiar agroecológica para o desenvolvimento sustentável das comunidades rurais. O objetivo dos serviços de ATER é promover qualidade de vida, através da inclusão socioprodutiva, do protagonismo juvenil, da educação contextualizada, do beneficiamento e comercialização dos produtos agropecuários 
regionais, do debate sobre questões fundiárias, da captação e manejo da água da chuva. Observa-se que o trabalho também visa contribuir para a consolidação da Convivência com o Semiárido e consequentemente com a redução da pobreza extrema, por meio da melhoria das condições de vida das famílias rurais, baseada na cooperação, visando à sustentação e permanência estável na terra, em harmonia com a natureza. ATER no semiárido: um encontro de possibilidades e desafios para o desenvolvimento rural do território de identidade Sertão São Francisco- Bahia (2016, p. 34) acesso em 21 de jun. 2018.

A concepção da Assessoria Técnica e Extensão Rural - (ATER) é um serviço de educação não formal, de caráter continuado, no meio rural, que promove processos de gestão, produção, beneficiamento e comercialização das atividades e dos serviços agropecuários e não agropecuários. Foi instituído pela Política Nacional de Assistência Técnica e Extensão Rural para a Agricultura Familiar e Reforma Agrária - (PNATER), cuja formulação e supervisão são de competência do Ministério do Desenvolvimento Agrário - (MDA), possuindo como principal instrumento de implementação a Lei $\mathrm{n}^{\mathrm{o}}$ 12.188, de 11 de Janeiro de 2010) (MDA, 2004).

Assim, fica evidenciado que esse setor é promissor e seus trabalhos são relevantes para o bem social, quando realizados por instituições sérias e responsáveis no manuseio de recursos alheios, sejam eles públicos ou privados.

\section{Metodologia Aplicada}

O processo de aprendizagem é muito amplo e busca minuciosamente maneiras de comunicação, interação, entendimento, raciocínio lógico que gradativamente leva o estudioso a indagações pertinentes a algo que ele quer compreender ou pesquisas mais aprofundadas num determinado campo. Podemos obter conhecimentos mediante a comunicação de outra pessoa, seja na forma escrita ou falada, sendo que essa última se resumirá sempre na escrita, por essa razão a larga importância da leitura para a formação acadêmica e simultaneamente pessoal.

Baseando-se notadamente no exposto acima, o processo de estudo para obter a aprendizagem desejada depende muito, a meu ver, dos métodos adotados pelo estudioso, pois uma leitura plena leva-o a "conhecer o mundo", e muitas vezes busca a compreensão de algo que ainda não tem explicação, sendo essa a razão que o leva a querer aprender. 
Com ênfase nesse trabalho, foi levada em consideração a pesquisa pura, porque se trata de um estudo sistemático motivado pela curiosidade, também permite criar novas questões daquilo que já se encontra produzido. Quanto ao método é qualitativa, pois buscam conhecimentos teóricos coletados de diversas fontes, documentos, pesquisas bibliográficas, e várias outras formas de obtenção de dados.

A pesquisa foi desenvolvida inicialmente pela metodologia bibliográfica, uma vez que, é inevitável qualquer espécie de pesquisa, sem o acompanhamento da busca por informações sobre o referido tema, seja em qualquer área, quer para a indagação do problema levantado, quer para a fundamentação da pesquisa.

Logo, a pesquisa foi realizada com a ajuda bibliográfica específica de alguns autores direcionada ao tema, para assim dar suporte e qualidade na análise dos referidos dados obtidos no caminhar do trabalho. Outrossim, livros e outros meios de informação sobre o tema foram buscados para embasar o estudo feito.

\section{Considerações Finais}

Mesmo em grande crescimento e ciente da ampla colaboração social, na sua importância e expansão na sociedade, ainda não conseguimos compreender o terceiro setor de maneira clara, forte, imperativa quanto ao Estado ou o Mercado. A compreensão obtida é, não raro, tumultuada por diversas terminologias adotadas. Ora o Terceiro Setor está associado a caridade, organizações sem fins lucrativos e não governamental, voluntariado, filantropia; ora é um conjunto de instituições que não objetivam lucros. Durante as várias leituras que contribuíram fortemente para o resultado desse trabalho, observamos que a ausência de conhecimentos técnicos e conceituais leva esse Setor a enfrentar sérias dificuldades financeiras e administrativas, por meio de planejamento inadequado, gerando avaliações distorcidas, mesmo entendendo-se a sua importância para o governo, mercado e sociedade.

Compreendendo isso, fazemos a seguinte pergunta: O terceiro Setor como o conjunto de instituições, independente dos objetivos deveria unificar e simplificar seu conceito, sua terminologia nas mais diferentes áreas do saber, que são: economia, administração, contabilidade, direito, sociologia, serviço social? Claro que esse questionamento se faz necessário um outro estudo, uma outra pesquisa. Assim, esse setor que é fundamental para a 
sociedade, para se tornar uma grande alternativa na sua gestão nas questões que movem a sociedade, precisará de um julgamento decisivo na apreciação de uma única nomenclatura para que possa ser vista de maneira sólida.

É visível, e por vezes repetitivo que ao longo do texto, a expressão Terceiro Setor foi citada diversas vezes, isso se deve a necessidade de buscar um entendimento direto, já que são vários enquadramentos existentes que fazem parte essas organizações.

Desse modo, torna-se imperativo entender a relevância da gestão transparente dessas organizações como mecanismo de contribuição à perenidade das organizações e sustentabilidade de seus projetos sociais desenvolvidos no âmbito do Terceiro Setor.

Segundo Fischer (2004, apud Silva et al., 2008), o Terceiro Setor vem ganhando importância e as organizações que o compõem passaram a ser consideradas, em alguns casos, tão ou mais importantes do que até mesmo as organizações públicas vinculadas ao Estado ou as organizações empresariais privadas e isso se deve, em parte, pela utilização de práticas administrativas modernas na gestão do Terceiro Setor, especialmente aquelas que mobilizam e/ou captam recursos financeiros.

Realmente os tempos mudaram e a busca por uma gestão mais eficiente e eficaz começou a substituir o amadorismo e direcionar um olhar mais pragmático e, consequentemente, mais profissional à atuação das organizações sem fins lucrativos. Nesse contexto, essas organizações passaram a buscar uma gestão mais profissional e percebeu-se a necessidade de técnicas de planejamento, gestão de recursos humanos, controle financeiro etc., oriundas da ciência da administração. No entanto, por não disporem de modelos próprios de gestão, essas organizações tendem a absorver práticas mercadológicas e também do setor público adaptando a sua realidade.

Em síntese, na compreensão da importância da gestão no Terceiro Setor, em um cenário de grandes desafios para essas atividades que envolve o ser humano, a boa gestão se torna um fenômeno universal no mundo moderno, em que as organizações precisam alcançar seus ideais, seus objetivos, fazendo imperar o princípio da continuidade, com o propósito de assegurar que as instituições devem perenizar no mercado, na contribuição da promoção do bem-estar social, quando visivelmente o Estado não torna isso possível. 


\section{Referências}

ATER no semiárido: um encontro de possibilidades e desafios para o desenvolvimento rural do território de identidade Sertão São Francisco- Bahia. http://www.irpaa.org/modulo/publicacoes/artigos.Acesso em 21 de jun. 2018.

BEZERRA FILHO, João Eudes. Contabilidade Pública: teoria, técnica de elaboração de balanços e questões. $2^{\mathrm{a}}$ ed. - Rio de Janeiro: Elsevier, 2006.

FISCHER, R. M.; BOSE, M. Tendências para a gestão de pessoas em organizações do terceiro setor. Asamblea Anual Consejo Latinoamericano de Escuelas de Admnistración. Santiago: CLADEA, 2005.

GUIMARÃES, LUCIANO. Finanças na ponta do lápis: entidades do Terceiro Setor que não adotam rigoroso planejamento financeiro - orçamentário corre o risco de se complicar no fechamento da contas. Filantropia, São Paulo, ano 7, n. 34, p. 24-25, 2008.

MALMEGRIN, Maria Leonídia. Gestão Operacional. Florianópolis: Ciências da Administração/UFSC, $\quad$ p. $1-21 . \quad 2012 . \quad$ Disponível http://www.moodle2.univasf.edu.br/posgraduacaoead/course/view.php?id=374. Acesso em 07 jun. 2018.

ROSA, Márcio Fernando Elias. Direito administrativo. 13 ed. São Paulo: Saraiva, 2012. (Coleção sinopses jurídicas: v. 19; parte I)

TACHIZAWA, Takeshy. Organizações não governamentais e terceiro setor: criação de ONGs e estratégias de atuação. São Paulo: Atlas, 2002.

TENÓRIO, Guilherme Fernando. Um espectro ronda o terceiro setor, o espectro do mercado: ensaios de gestão social. $3^{\text {a }}$ Ed. Ijuí: Ed. Unijuí, 2008. 192 p.

ZANELLA, Liane Carly Hermes. Metodologia de estudo e de pesquisa em administração. 2. ed. reimp. - Florianópolis : Departamento de Ciências da Administração / UFSC, 2012.pág.105-160.Disponível em http://www. moodlle2.univasf. edu.br/posgraduacaoead/ couse/view.php?id=370. Acesso em 05 out.2017.

Como citar este artigo (Formato ABNT):

BRITO, Micheiane Felix de; TAVARES, Maria Natália da Silva; SOARES, Rita Cristiane Ramacciotti Gusmão. Importância do Terceiro Setor como alternativa de Gestão no aparato social. Id on Line Rev.Mult. Psic., 2018, vol.12, n.42, p. 422-435. ISSN: 1981-1179.

Recebido: 17/09/2018;

Aceito: 29/09/2018 